\title{
On the distribution of debt and taxes
}

\author{
Francesco Caselli* \\ Gradtate School of Business, University of Chicago, Chicago, IL 60637, USA
}

Received 31 December 1994; accepted 31 August 1996

\begin{abstract}
This paper studies public-debt runs under alternative assumptions on the distribution of taxes among tax bases, the distribution of debt among classes of taxpayers, and the distributive preferences of the govenıment. Asymmetries in the distribution of taxesarising, for example, from income-tax evasion by some categories of taxpayers-increase the likelihood of a confidence crisis on the public debt. On the other hand, perhaps surprisingly, the probability of a run followed by default is decreasing in the degree of identification of the government with a specific constituency, whereas it is a maximum when the policymaker is a coalition where all social groups are represented equally. Empirical evidence from a sample of high-debt OECD countries is found to be broadly consistent with the theoretical results: regression results indicate that 'coalition premia' and 'tax-imbalance premia' appear to contribute to the interest cost of the public debt. (C) 1997 Elsevier Science S.A.
\end{abstract}

Keywords: Public debt; Tax imbalances; Coalitions; Risk-premia; Default

JEL classification: E62; $\mathrm{H} 26 ; \mathrm{H} 63$

\section{Introduction}

The recent accumulation of high levels of public indebtedness in several industrialized countries has prompted a renewal of interest in the macroeconomic implications of large public debts. Among the new areas of research, a paricularly fruitful one addresses the issue of multiple equilibria in the presence of potential

${ }^{*}$ Corresponding author: e-mail: francesco.caselli@gsb.uchicago.edu 
confidence crises. This literature recognizes that a 'run on the debt', generated by a wave of panic, may well be self-fulfilling. In fact, a government that would otherwise roll its debt over for a long sequence of periods may find itself unable to repay the entire amount outstanding, in the face of a refusal by the public to renew expiring issues. Hence, these contributions have introduced a new notion of debt sustainability. Namely, they point out that the public debt may become unsustainable-in the sense that a confidence crisis triggers a default-even if it is sustainable in the traditional sense, i.e. that it is less than or equal to the present value of future taxes (minus expenditures).'

After pointing out this additional potential problem of having a high public debt, this literature-initiated by Calvo (1988)--has started looking at the solutions. Hence, Alesina et al. (1990); Giavazzi and Pagano (1990) have shown how, for a given stock of debr; the probability of a self-fulfilling confidence crisis depends on the structure of the debt: maturity, currency composition, timing of issues. In doing so, they have provided a bridge between confidence crises and public-debt management, another area of active recent research. ${ }^{2}$

Instead of looking at confidence crises and the composition of the debt, this paper analyzes the relation among confidence crises, the distribution of taxes across taxpayers and tax bases, and the distribution of the deht across different groups of investors. 1 start by asking what are the implications-for a country with a high public debt—of asymmetries in taxation, particularly those asymmetries that cannot be justified on 'optimal-tax' grounds. The main result is that in an economy where such asymmetries are present a self-fulfilling confidence crisis on the public debt is more likely than in the corresponding 'representative consumer' economy (where such asymmetries are trivially absent). The basic intuition is that, if a 'run' on the debt takes place, the government has two options: to default, or to raise enough tax revenue to pay off the entire existing stock of debt. The second alternative is much less painful if the 'burden' can be distributed evenly among all tax bases than it is if only some of them have to bear it. As a consequence, the 'temptation' to default is greater in an asymmetrically taxed economy.

If the distribution of taxes matters, the distribution of debt holdings is likely to matter, too. However, unlike conventional taxes, debt default is a lump-sum tax. Therefore, in order for the distribution of the debt to influence the government's decision problem it is necessary to move from a characterization of the policymaker as solely concerned with efficiency, to one in which its attitudes towards income and wealth distribution are explicitly considered.

When I do this some counter-intuitive insights emerge. In particular, I find that the probability of having an equilibrium with default is decreasing in the degree of polarization of the government's preferences. In the limit, if the government is exclusively concerned with the welfare of only one group of taxpayers/debt

\footnotetext{
${ }^{1}$ These results echo similar ones in the theory of bank runs (see, for example, Diamond and Dybvig, 1983).

${ }^{2}$ Caselli (1992) surveys recent research on public-debt management.
} 
holders, there cannot be an equilibrium with default. On the other hand the probability of default is at its maximum when the government gives equal weight to all social groups. There are also more intuitive results. Namely, for given distributive preferences by the government, the probability and the extent of default tend to vary inversely with the share of debt held by the constituency to which the government is 'closer'.

These results follow from the different attitudes towards redistribution by different governments. The more partisan the government, the grcater the weight given to distributive goals. Tax policy is a better redistributive tool than debt policy because it can be targeted more finely. In particular, it is possible to design tax or tax-credit schemes that affect only specific groups of taxpayers, whereas it is almost impossible to use debt default selectiveiy: debt default will in general hit everyone, including those in the government's constituency. Hence, the more distributive goals weigh in the policymaker problem, the more the policymaker will be averse to default.

At the opposite extreme, a government that gives equal weight to all social groups should be interpreted as a coalition government, with partners in the ccalition carrying equal power. This power is used by coalition members to reciprocally block any attempt to implement redistributive policies. With redistribution ruled out, the second best thing for any party to do is to minimize the tax distortions suffered by its own constituency. As a result, coalition governments will view debt default as an additional source of revenue, and will be tempted to use it in conjunction with conventional taxes to achieve a minimum level of global distortions.

By uncovering a further reason why high public debts are more destabilizing in countries run by coalitions, this paper complements other contributions that have a similar implication, such as the 'war of attrition' models of Alesina and Drazen (1991); Drazen and Grilli (1993); Spolaore (1993), among others. ${ }^{3}$ In war of attrition models the public debt follows an unstable path, because each social group tries to shift the burden of fiscal adjustment on other coalition members. Hence, these models focus on the strategic aspects of the relationship between members of a coalition. The other feature of multiparty government, however, is that radical redistribution is made difficult by the need of holding the coalition together. As a result, a coalition's policy is often guided by the goal of spreading social costs, in a way that does not trigger the veto of any of the constituencies backing the government. ${ }^{4}$ By abstracting from strategic issues my model focuses on the cost-spreading aspect of coalitions, and shows how this feature can

\footnotetext{
${ }^{3}$ That coalition governments are associated with greater fiscal instability is a rather solid stylized fact (c.g., Roubini and Sachs, 1989).

${ }^{4}$ The twofold nature of coalitions is noted by Alesina and Rosenthal (1995) (p. 248): "Can we then conclude that coalition governments bring more stability in economic policymaking? In some sense the answer is yes, because coalition governments avoid sharp partisan changes. On the other hand, coalition governments may bring 'gridlock' and legislative inaction" (italics added).
} 
translate into a temptation to default on the public debt. Conversely, by (typically) assuming an exogenous distribution of the costs of stabilization (the only uncertainty being who will carry the greatest weight), war of attrition models abstract from the cost-spreading incentives inherent in multiparty coalitions.

The relationship between default and the government's distributive preferences is also studied by Aghion and Bolton (1990); Milesi-Ferretti (1995). In these two period models right-wing incumbents use the size or the composition of the debt in order to increase the number of voters that would be hurt by a default. Since the left-wing party is more prone to default, this policy enhances the right-wing incumbent's reelection chances. Hence, the focus of these studies is different from the one in the present paper. Whereas they look at how the possibility of default affects the electoral game, the model in this article explores the conditions that make a confidence crisis more likely.

The empirical implications of this paper's results are straightforward. Ceteris paribus, tax imbalances make public debts riskier. Also, socially non-partisan or coalition governments make debts riskier. Thus, we should expect 'tax-imbalance premia' and 'coalition premia' to enter the computation of the more general 'credit risk' premium. In order to test these predictions, I use data from a panel of high-debt OECD countries to ask: (i) whather coalition governments tend to incur higher interest costs to service their debts relative to singie-party governments, and (ii) whether economies with higher indicators of tax-imbalances tend to be associated with higher interest costs on the public debt. These questions are asked holding constant a number of other potential determinants of the cost of debt servicing. As I obtain positive answers to both I conclude that the empirical evidence supports the ideas presented in tiis papor.

Section 2 uses a simple version of the model in Alesina et al. (1990) to look at the relation between the structure of the tax systein and public confidence, when the government is 'benevolent', i.e. only interested in general sricial welfare. In Section $3 \mathrm{I}$ extend the analysis to include distributive preferences, and look at the role of the distribution of debt holdings. Section 4 tests the model on a sample of OECD countries. Section 5 concludes.

\section{Debt policy under an imbalanced tax system}

This section shows that, in assessing the implications of a high public debt, attention should also be given to the distribution of the taxes that are levied to finance interest payments. In particular, define an imbalanced tax regime as a regime under which some tax bases or groups of taxpayers are more heavily taxed than others, whereas a balanced regime imposes similar tax rates on all bases. From the tax-base perspective, imbalances between direct and indirect taxation, property and income taxes, taxes on capital income and taxes on labor income, are the most obvious examples. One example of a tax imbalance aniong groups of 
taxpayers is the case in which, for the purposes of regional redistribution, some geographical areas of an economy receive tax credits or other tax incentives for which other areas must compensate. Another empirically important case is when the same tax base is taxed with a different collection technology according to some individual characteristics of the tax payer. For example, taxes on labor income are usually ascertained with different procedures in the case of wage-labor and in the case of self-employment, and this will typically lead to differential opportunities for tax evasion. Whatever the source of the tax imbalance, I will argue that, for a given high level of debt, a confidence crisis on the ability or willingness of the government to fulfil its obligations is more likely to occur under an imbalanced than under a balanced tax regime.

Consider the problem of a government that must decide on how to firance its interiemporal budget. Without loss of generality, public consumption is assumed to be zero in every period, but the government must raise funds to service a given stock of public debt, inherited from the past. The sources of income for the government are debt default and conventional taxation. There are two bases for conventional taxation, $i$ and $j$, and the government can impose different tax rates on them.

These assumptions result in the following budget constraint for period $t$

$$
\tau_{i t}+\tau_{j t}=b_{t}-q_{t+i} b_{t+1}-\theta_{t} b_{t}
$$

where $\tau_{i t}$ and $\tau_{j t}$ are the amounts raised by taxing, respectively, tax bases $i$ and $j$; $b_{t}$ is the stock of debt outstanding at the beginning of period $t ; q_{t+1}$ is the price at which the government can sell a promise to deliver one unit of the (unique) good in period $t+1 ; \theta$ is the fraction of debt defaulted at time $t$. Notice that this budget constraint implicitly assumes that all debt is one-period debt. ${ }^{5}$

By assuming that investors are risk-neutral we can write a Fisher equation that allows us to determine the price at which government bonds sell at time $t$, as a function of the public's expectations:

$$
q_{t+1}=\beta\left(1-\theta_{t+1}^{e}\right)
$$

where $0<\beta<1$ is the (exogenous) price of a riskless alternative asset-say foreign, low-debt government bonds-promising delivery of one unit of the good after one period, and the superscript $e$ indicates one-period-ahead expectation. Under the assumption of rational expectations any equilibrium must satisfy $\theta_{l}^{l}=\theta_{t}$ for every $t$.

\footnotetext{
"It is also implicitly assumed that the public debt is indexed to the price level, so that $\theta$, is outright repudiation. However, one may reinterpret Eq. (1) as a (very crude) representation of nominal-debt default via inflation: in each period the government engineers an inflation that reduces the real value of the debt by a fraction $\theta_{1}$, and then uses taxes and new debt issues to finance the remainder.
} 
In determining the combination of $\tau_{i t}, \tau_{j}$ and $\theta_{t}$ it will use in any period, the government traides off the welfare costs of each of these taxes. Conventional taxes induce the usual distortions in individuals' behavior. Default, in turn, implies economic disruptions such as banking failures, breakdown of intermediation and the like. These costs are captured by the loss function

$$
\sum_{i=0}^{\infty} \beta^{t} L\left(\tau_{i t}, \tau_{j t}, \theta_{t}\right) \equiv \sum_{i=0}^{\infty} \beta^{\prime}\left[z\left(\tau_{i t}, \tau_{j t}\right)+v\left(\theta_{t}\right)\right]
$$

where I have implicitly assumed that financial assets are priced so as to reflect the utility time-discount rate. This assumption avoids corner solutions in which the public holds only one of the two assets. ${ }^{6}$

The loss function in Eq. (3) is given structure by the restrictions

$$
z_{1}(\cdot, \cdot)=z_{2}(\cdot, \cdot) \quad z_{12}(\cdot, \cdot)=0 ; z_{i}(\cdot, \cdot)>0 \quad z_{i i}(\cdot, \cdot)>0 \quad i=1,2
$$

where $z_{i}$ and $z_{i j}$ denote, respectively, first and second partial derivatives. The first two restrictions in Eq. (4) can be generalized. The last two restrictions are standard. As for the costs of default, I follow Alesina et al. (1990) in assuming

$$
v\left(\theta_{t}\right)=0 \text { if } \theta_{t}=0 ; v\left(\theta_{t}\right)=\kappa \text { otherwise }
$$

In other words, the costs of repudiation are independent of the amount defaulted. An immediate consequence of Eq. (5) is that, if default ever takes place, it is total and occurs in the first period. Hence, we can restrict the analysis to the outcome of period 0 .

Under the assumed conditions, minimization of Eq. (3) clearly requires $\tau_{i t}=\tau_{j t}$ at any $t$ : optimal tax smoothing is achieved by a balanced tax regime. To characterize rational expectations equilibria under such a regime, consider first the optimal policy when the public expects no repudiation, i.e. when $q_{t}=\beta$. If the government does not default, the optimal policy involves rolling over the debt forever, using time-invariant taxes to meet interest payments. The corresponding loss is

$$
\kappa \equiv \frac{z\left(\frac{b_{0}(1-\beta)}{2}, \frac{b_{0}(1-\beta)}{2}\right)}{(1-\beta)}
$$

This policy of no default is a rational expectations equilibrium only if $\underline{\kappa}<\kappa$, i.e. it is less costly than default.

${ }^{6}$ Eq. (3) should be thought of as a 'reduced form'. The 'structural form' is one that starts from individuals' utility maximization, conditional on the tax rates. It then derives indirect utility functions that depend on $\tau_{i}, \tau_{j}$ and $\theta$. These functions are then substituted into a government's welfare function which is originally expressed as a weighted sum of individual direct utilities. I have chosen this shoricut to save on computation. 
Suppose now that a confidence crisis takes place. Since default is always complete, a confidence crisis iniplies $\theta_{1}^{l}=1$, or $q_{1}=0$. As a consequence, if the government does not want to fulfil the public's expectations it must repay the entire debt by raising taxes $2 \tau_{0}=b_{0}$. The cost of not fulfilling the crisis is thus

$$
\bar{\kappa} \equiv z\left(b_{0} / 2, b_{0} / 2\right)
$$

Therefore, a self-fulfilling confidence crisis can be part of an equilibrium only if $\kappa<\bar{\kappa}$. By the convexity of $z$, it immediately follows that $\bar{\kappa}>\underline{\kappa}$.

What happens, instead, if the government can determine the total level of conventional taxation, but not the relative weights of taxes on the two tax bases? In other words, the government controls $\tau_{i t}+\tau_{j j}$, but the ratio $\tau_{i t} / \tau_{j t}$ is exogenous. Although this assumption is clearly extreme, it does capture the idea that governments are constrained in their choice of the distribution of taxes across tax bases, as discussed at the beginning of this section. For ease of exposition, I will focus on the extreme case in which $\tau_{i t}=0$ in every period. However, all the qualitative insights arising from the analysis of this case extend to any unbalanced regime.

If no confidence crisis occurs, the optimal policy contingent on not using default is to roll over the debt forever, financing interest payments with taxes on base $j$. The corresponding loss is

$$
\kappa^{*} \equiv \frac{1}{1-\beta} z\left(b_{0}(1-\beta), 0\right)
$$

and $\kappa^{*}<\kappa$ is the condition required for there to exist an equilibrium without confidence crises. Resisting a confidence crisis, instead, involves taxing tax base $j$ for the full amount of debt outstanding. The associated cost is

$$
\overline{\kappa^{*}} \equiv z\left(b_{0}, 0\right)
$$

Thus, a self-fulfilling confidence crisis can be part of the equilibrium if and only if $\kappa<\overline{\kappa^{*}}$. Once again, $\kappa^{*}>\kappa^{*}$.

The interest of this analysis emerges when we compare the structure of equilibria in the balanced and in the unbalanced regime. The qualitative results are summarized in Fig. 1. As the figure illustrates, we have

$$
\underline{\kappa}^{*}>\underline{K} \text { and } \overline{\kappa^{*}}>\bar{\kappa}
$$

which can readily be verified from Eqs. (6)-(9) and the restrictions in Eq. (4).

The result in Eq. (10) can be interpreted as follows. First, under an imbalanced tax regime, a benevolent government is more prone to default than under a balanced regime. This is captured by the fact that $\kappa^{*}$ is to the right of $\underline{\kappa}$. Second, under an imbalanced regime the government is less likely to resist a confidence crisis. This is the interpretation of $\overline{\kappa^{*}}$ being to the right of $\underline{\kappa}$. These two results follow very intuitively from the convexity of the tax-distortion function. In 


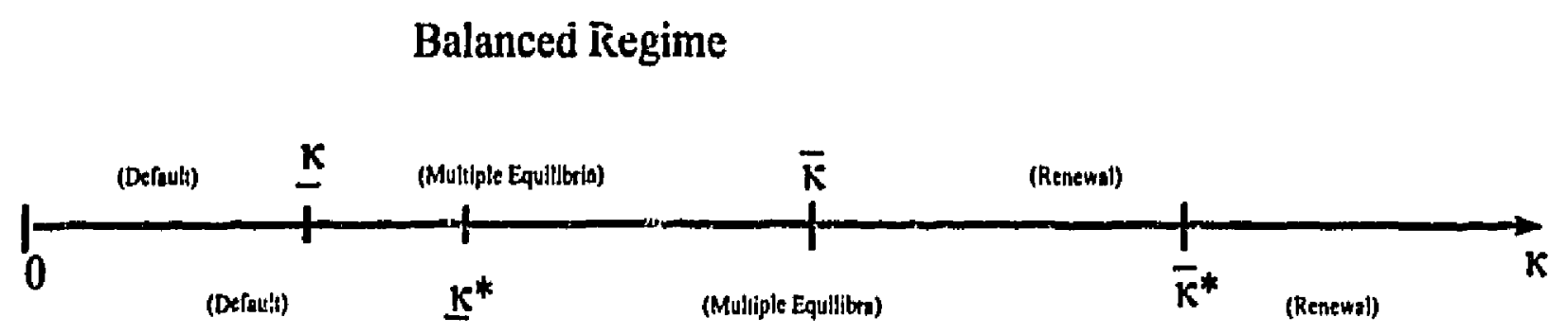

\section{Unbalanced Regime}

Fig. 1. Determination of equilibrium in Balanced (top) and Unbalanced (bottom) tax regime.

particular, tax imbalance exacerbates the welfare costs of debt service, since it prevents the government from distributing the burden across all social groups. As a result, even a government that would be ready to sustain those costs if it could use taxes in a balanced fashion, might be induced to default when constrained to an imbalanced distribution. The third result shown in Fig. 1 is that

$$
\overline{\kappa^{*}}-\underline{\kappa^{*}}>\bar{\kappa}-\underline{\kappa}
$$

This relationship, which is proved in Appendix A, is perhaps the most intriguing insight from the analysis of this section. It says that what we may term the 'area of uncertainty'-the range of values of $\kappa$ for which there are multiple equilibria-is magnified by an imbalanced tax system. Suppose that we describe the probability of a self-fulfilling confiderice crisis as the product of the unconditional probability of a run on the debt and the probability that $\kappa$ falls into this area of uncertainty. It seems reasonable to assume that the latter is correlated with the length of the interval. Then, we have that the probability of a confidence crisis is higher under an imbalanced than under a balanced tax regime.? In Section 4 I present some empirical evidence in support of this prediction.

\section{Debt policy under distributive preferences}

In the previous section the government has been modeled as a 'benevolent dictator'. In such a setting, the distribution of debt holdings among different agents is irrelevant. For, disruptions aside, debt default is (ex post) a lump-sum tax: hence, its effects are independent (for the government's purposes) of whether they are borne sy many or a few citizens. The distribution of the debt is relevant, however, wher the government identifies itself with a specific group of citisens, or constituency. In this case, intuition would suggest that debt held mainly by

The same interpretntion of the size of the interval is used by Alesina et al. (1990) to show that long-term debt reduces the likelihood of a self-fulfilling confidence crisis. 
members of the government's constituency will represent a further discouragement (besides general economic disruptions) from debt default, while a concentration of the debt with the 'other' group will increase the temptation to default. Although this simple intuition is broadly borne out by the results of this section, the analysis offers a richer and subtler set of insights. To model distributive issues, I restrict the interpretation of $i$ and $j$ to the case of two groups of agents (capitalists and workers, employed and self-employed...) that are taxed at different rates $\tau_{i r}$ and $\tau_{j r}$. In addition, each group is initially endowed with a share of the total amount of debt $b_{0}$ : respectively, $b_{i 0}$ and $b_{j 0}$, with $b_{i 0}+b_{j 0}=b_{0}$. Any tax on the public debt will be general, and not specific to the group to which the holder belongs. ${ }^{8}$ The initial distribution of the debt is known to the government, and is exogenous.

'The government's objective function in Eq. (3) is modified by the following specification of the per period loss:

$$
L\left(\tau_{i t}, \tau_{j t}, \theta_{t}\right) \equiv \frac{1}{2}\left\{\alpha\left[A \tau_{i t}^{2}+1\left(\theta_{t}>0\right) b_{i t}^{2}\right]+(1-\alpha)\left[A \tau_{j t}^{2}+1\left(\theta_{t}>0\right) b_{j t}^{2}\right]\right\}+v\left(\theta_{t}\right)
$$

where $1(\cdot)$ is an indicator function taking value 1 when its argument is true and 0 otherwise, and $v(\cdot)$ is as in Eq. (5). The coefficient $\alpha$-restricted between 0 and 1 -captures the government's distributive preferences: $\alpha=1(\alpha=0)$ implies that the government only cares for group $i(j)$, and $\alpha=1 / 2$ stands for a coalition government whose members have identical parliamentary or congressional strength. ${ }^{9}$ The distributive preferences of the government are independent of the initial distribution of the debt.

In the loss function in Eq. (12) the cost of default is quadratic in the amount of debt held, but discontinuous in the rate of default. This specification is useful

\footnotetext{
${ }^{8}$ The assumption of a uniform default rate is most easily justified when interpreting the model in terms of default by inflation: the government cannot engineer different inflation rates for different groups. In the case of outright repudiation, instead, selective default may be possible if there exists debt of different categories. De Broeck (1991), for example, notes that the Belgian government issues debt instruments tailored to different categories of investors. Given the kind of market segmentation that this generates (basically, institutions vs. families), however, it seems difficult to associate different debt instruments to different tax-paying constituencies. It is less easy to dismiss the possibility of selective default between foreign and domestic currency debt.

${ }^{9}$ Similatily, values for $\alpha$ strictly between 0 and 1 , and different from $1 / 2$, can be interpreted as coalition governments whose members have unequal electoral strength. That $\alpha$ is time invariant is clearly a restrictive assumption. Although modelling time-varying preferences is beyond the scope of this paper, in reality governments with different distributive objectives may alternate in office. One way of reinterpreting $a$, that makes its constancy less restrictive, is as a description of the political institutions of a country. In particular, one might argue that a democratic regime with proportional representation imposes the maximum effort at 'consensus building' $(\alpha \sim 1 / 2)$, whereas in a dictatorship the constituency behind the government takes almost all ( $\alpha=0$ or 1). A democratic but majoritarian regime would be an intermediate case. These institutional features are constant for long periods of time.
} 
because it captures the idea that a constituency's aversion to debt default is an increasing and convex function of its pecuniary loss from default. At the same time the discontinuity in $\theta$ delivers the same 'all-or-nothing' result on the period 0 default rate that we have already exploited in the previous section. ${ }^{10}$ The shift parameter $A$ allows the marginal welfare effect of being taxed to differ from the one of being defauited on.

To characterize debt policy equilibria in this model we start by calculating the welfare loss in period 0 if the government decides to default:

$$
K(\alpha, x)=\frac{1}{2} b_{0}^{2}\left[\alpha x^{2}+(1-\alpha)(1-x)^{2}\right]+\kappa
$$

which is the loss function with $\theta_{0}=1, \theta_{t}=0$ for $t \neq 0, \tau_{i t}=\tau_{j t}=0$ for every $t$, and $x \equiv b_{i 0} / b_{0}=1-b_{j 0} / b_{0}$. Hence, the cost of default depends on the interaction of the government's partisan motives with the distribution of the debt, as captured by the fraction of debt held by constituency $i$.

Suppose now that debt is serviced by conventional taxes. If any taxes are levied in period $t$, Eq. (12) implies that

$$
\frac{\tau_{j t}}{\tau_{i t}}=\frac{\alpha}{1-\alpha}
$$

This shows how the government distributes the burden of debt service according to its partisan preferences. If no confidence crisis takes place in period 0 the tax smoothing principle applies, and the debt will be rolled over indefinitely. A constant flow of payments $(1-\beta) b_{0}$ will be financed by time-invariant taxes distributed as in Eq. (14). By substituting the resulting values of the tax rates in the intertemporal loss function, we can compute the cost of not defaulting in period 0 , when the public expects no default. After some simplification, this cost turns out to be

$$
\underline{K}(\alpha)=\frac{1}{2} A \alpha(1-\alpha)(1-\beta) b_{0}^{2}
$$

If a confidence crisis takes place in period 0 , default can be avoided by repaying the debt in full at once. Total taxes are $b_{0}$ in the first period, and 0 afterwards. The corresponding loss is

$$
\bar{K}(\alpha)=\frac{1}{2} A \alpha(1-\alpha) b_{0}^{2}
$$

The cost of not defaulting is obviously independent of who owns the debt. However, it is affected by the partisanship parameter $\alpha$. In particular, notice that the quantity $z \equiv \alpha(I-\alpha)$ is maximized at $\alpha=1 / 2$, and minimized (in the allowed

\footnotetext{
${ }^{10}$ Simply note that both the distributive and the general economic disruptions from default are independent of $\theta$, as long as the default rate is greater than 0 .
} 
range of variation) at values of $\alpha$ of 0 and 1 . Hence, we can interpret this quantity as an inverse measure of the intensity of the partisan motive: the greater $z$ the more even the distribution of power within the coalition. The losses in Eqs. (15) and (16) are monotone in $z$. The intuition is that an extremely partisan government will shift most of the burden of interest payments onto the opposite constituency. Since the welfare of the latter carries little weight in the loss function, the total loss will also be low. A coalition government instead will distribute the burden, and both constituencies will suffer welfare losses. Since both of these losses are important to the policymaker, the corresponding government's loss is high as well.

The structure of the solution is reminiscent of that of Section 2. If the cost of default $K(\alpha, x)$ is less than the cost of indefinitely rolling the debt over, $\underline{K}(\alpha)$, the only possible outcome has total default at time 0 . If $K(\alpha, x)$ is above $\bar{K}(\alpha)$, i.e. the cost of repaying the debt at once, then only indefinite rolling over can be an equilibrium. Finally, if $\underline{K}(\alpha) \leq K(\alpha, x) \leq \bar{K}(\alpha)$ we have multiple equilibria: if the public is confident $\left(\theta_{0}^{e}=0\right)$ the debt is rolled over, if a confidence crisis occurs $\left(\theta_{0}^{e}=1\right)$ the debt is defaulted on. "However, the relative position of $K, \underline{K}$ and $\bar{K}$ now not only depends on the economywide disruption measure $k$, but also on the interaction of partisanship and debt holdings.

Some features of the solution are immediately apparent. First, notice that, irrespective of the distribution of the debt, an extremely partisan government $(\alpha=0$ or $\alpha=1)$ will never use debt default. This can be seen by the fact that $\bar{K}$ falls to zero in this case, while $K$ takes the value of $\kappa$. On the other hand, the closer $\alpha$ is to $1 / 2$, the more to the right the two triggers $\underline{K}$ and $\bar{K}$ move. Keeping with the spirit of Section 2, we can interpret these findings as revealing a greater proneness to default, and a smaller ability to resist a confidence crisis by a bipartisan government relative to a partisan one. In addition, the quantity $\bar{K}-\underline{K}$ is monotone in $z$. Hence, coalition governments magnify what I have called the area of uncertainty: the probability of a self-fulfilling confidence crisis is at its maximum when the government does not (or cannot) pursue distributive aims. ${ }^{2}$

The above features of the solution do not depend on the distribution of the debt. However, this does not imply that whether default will actually occur is independent of the pattern of debt holdings. On the contrary, because the distribution of the debt influerces the cost of default, it also contributes to determine whether the cost of default falls inside or outside the interval $[\underline{K}, \bar{K}]$. A richer characterization of the solution is thus needed, and is presented in Fig. 2. In

"That $\bar{K}>\underline{K}$ follows trivially from Eqs. (15) and (16), and the restriction $0<\beta<1$.

${ }^{12}$ It is useful to compare my results on equal-weight coalitions (maximum instability) with the case in which the 'burden of adjustment' is equally distributed in war of attrition models. In those models, equal sharing leads to immediate termination of the war (maximum stability). The difference stems from the fact that in war of attrition models there is no choice of instrument: there is only one way (conventional taxation) to distribute welfare losses. In the present paper, instead, once it has been decided that losses are to be shared, there remains the choice between conventional taxation and debt default. It is this choice that leads to the temptation to default. 


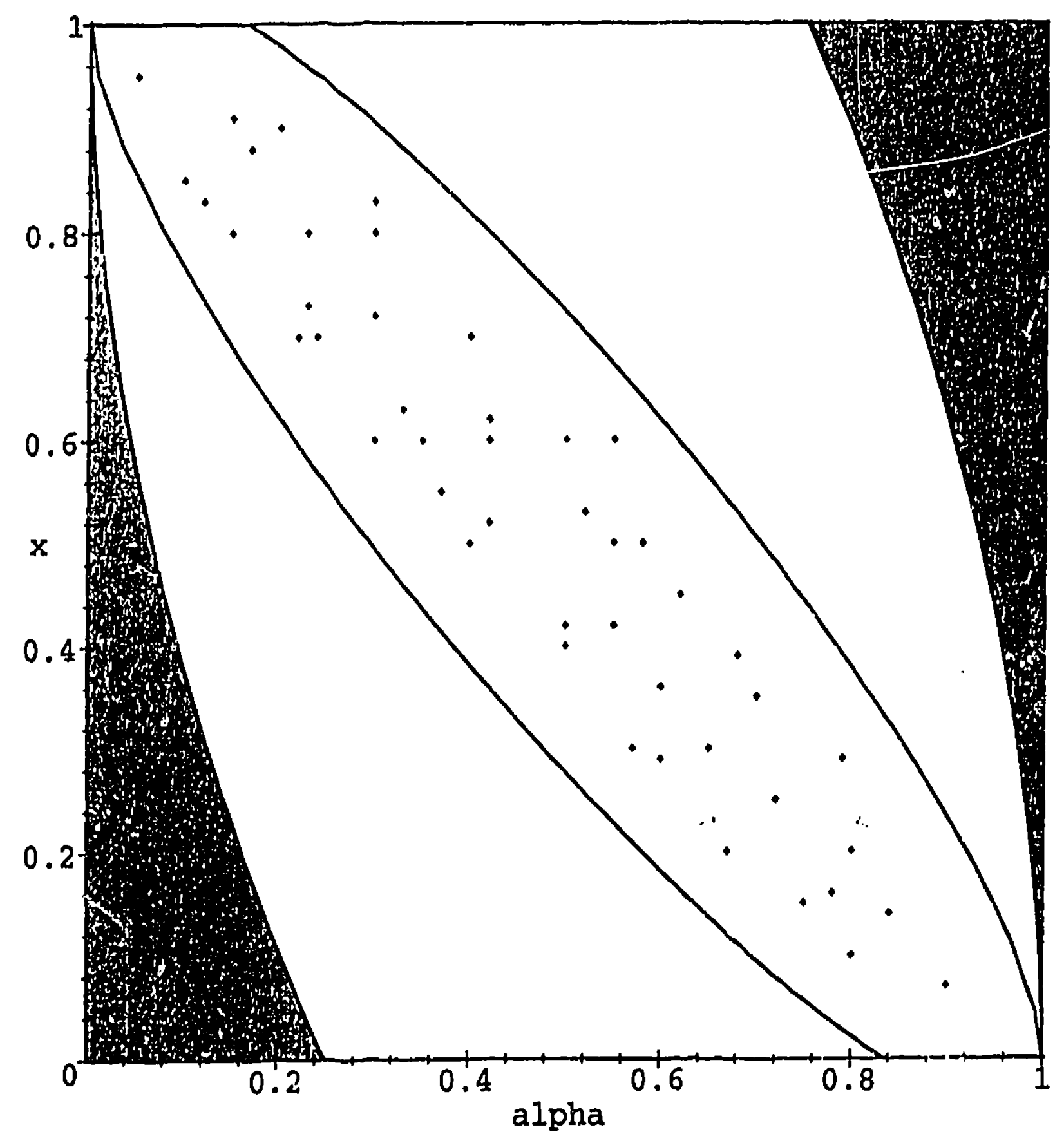

Fig. 2. Determination of equilibrium by governments' partisonship $(\alpha)$ and debt-ownership shares $(X)$.

the figure, the horizontal axis measures $\alpha$, while the vertical axis shows values for $x$, the share of debt initially held by type $i$ agents. The picture has the following interpretation. The outermost, darker areas represent combinations of $\alpha$ and $x$ such that default never takes place. The intermediate, white areas correspond to parametric values that generate multiple equilibria. Finally, the innermost, shaded section is the locus of $(\alpha, x)$ pairs such that default will always happen. ${ }^{13}$

The picture confirms that at extreme values for $\alpha$ default does not occur, irrespective of the distribution of the debt. On the other hand, there is no pattern of debt distribution such that an equal-weight coalition is sure to avoid default. On the contrary, the equal-weight coalition is the one which will certainly repudiate

${ }^{13}$ Technically, Fig. 2 plots the contours at level 0 of the functions $K(\alpha, x)-\bar{K}(\alpha)$ and $K(\alpha, x)-\underline{K}(\alpha)$, for an arbitrary choice of values for $A, k$ and $\beta$ (respectively, 4,0 and 0.7 ). The qualitative features of the picture are unaffected by alternative choices. 
for the widest range of debt-ownership shares. This is shown by the fact that the vertical distance between the bounds of the central, shaded area is maximized at $\alpha=0.5$. It is also interesting to look at the picture starting from tine debt shares. Suppose, for example, that constituency $i$ owns a relatively small portion of the debt, say $20 \%$. Then, as intuition suggests, for governments sufficiently close to group $j$ ( $\alpha$ between 0 and 0.2 ), there is no default. For coalitions that range from quite favourable to the $j$ 's to slightly favourable to the $i$ 's, however, multiple equilibria arise, and a confidence crisis triggers default. A mildly $i$-backed coalition is sure to default, as are all other coalitions up to approximately $\alpha=0.95$. More broadly, Fig. 2 should be regarced as a reference for assessing the existence and the size of a default-risk component arising from the interaction of distributive goals and distribution of debt, for a given high-debt country. ${ }^{14}$

\section{4. 'Tax-imbalance premia' and 'coalition premia'}

In Section 2 we have seen that an imbalanced tax system can make a self-fulfilling confidence crisis more likely. Hence, under an imbaianced tax system investing in government bonds is riskier and, ceteris paribus, we should expect countries with an ill-distributed fiscal pressure to pay higher interest rates than countries whose tax system is well balanced. This credit-risk factor may be called the 'tax-imbalance premium'. The second main insight of the paper is that we should expect the public debts of countries with coalition governments to be seen as riskier investments, and hence to be associated with higher interest rates, than those of countries in which a well-defined group, or party, holds a clear majority. Accordingly, I will call this component of the risk premium the 'coalition premium'. This section provides empirical evidence that lends some support to both of these predictions.

I combine data from two sources. From the OECD Economic Outlook I derive annual data on government finances, macroesonomic performance and employment structure for several OECD countries from 1960 to 1994. From a new data set created by Kontopoulos and Perotti (1997) I derive various characterizations of the political composition of the government ruling each country in each year of the sample. ${ }^{15}$ Hence, the analysis is panel in nature, with country-year data points

\footnotetext{
${ }^{14}$ In a previous version of this paper (available upon request) I provide a more general treatment with continuous costs of default. The main results are as follows. The equilibrium typically features partial debt default $(0<\theta<1)$ in the first as well as in any subsequent period. The default rate tends to vary inversely to the share of debt held by the constituency to which the government gives a greater weight. Equal-weight coalitions tend, on average, to have the highest default rates. Hence, the extended model confirms the basic finding of a greater proneness to default by a coalition government.

${ }^{15}$ Based on raw data, Kontopoulos and Perotti (1997) have constructed a number of variables that capture the political-economic nature of the government in each country-year. See Kontopoulos and Perotti (1997) for a description of the data set.
} 
constituting the units of observation. The theory presented in Section 2 and Section 3 is only meaningful for economies with a high public debt. If the public debt is small the costs of repayment are never high enough to make a confidence crisis self-fulfilling. Hence, coalition premia and tax-imbalance premia are only expected to arise in high-debt countries and periods. To make this notion operational I limit my sample to those country-year data points in which the gross debt to GDP ratio is above the Maastricht Treaty threshold of $0.6 .^{16}$ This is, of course, a rather arbitrary definition of what constitutes a 'high' public debt, and I report later on many checks on the robustness of the results to altcinative criteria for inclusion in the sample. There are about 150 country-year observations that fulfil the 0.6 criterion in the data set. However, missing values fur the variables included in the regression (most notably the dependent variable) will further reduce the final sample size to 105. The 105 data points are: Belgium 1970-1991, Canada 1985-1991, Denmark 1983-1985, Denmark 1991, Greece 1988-1991, Ireland 1977-1991, Italy 1975, Italy 1978-1979, Italy 1981-1991, Japan 19821991, Netherlands 1983-1991, Norway 1978-1979, Portugal 1987-1991, Sweden 1982-1986, United Kingdom 1970-1977.

My dependent variable is the unit interest cost of the public debt. I obtain this measure by dividing general government gross interest expenditure by the stock of gross public debt outstanding at the end of the previous year. At any point in time, the stock of debt is made up of securities of many different types and maturitiss, each of which is associated with a different interest rate. My measure of the unit cost of debt is therefore an average of the interest rates the government pays on the bonds it issued. weighted by the relative share of the various types of bonds in the stock of outstanding debt. I report below on robustness checks involving alternative choices of the dependent variable. As explanatory variables I use a number of coalition indicators and tax-imbalance proxies, which I discuss in greater detail below. In order to hold constant other potential determinants of the interest cost of debt, each regression also includes, as control variables, the inflation rate, the stock of public debt, the primary surplus (both as percentages of GDP) and the real growth rate. The choice of these controls is based on Caselli et al. (1996), to which I refer the reader for a detailed discussion. ${ }^{17}$ Given the nature of the data, it is crucial to include country dummies in the regression. The ideal specification would also use year dummies, but this involves a substantial loss of

\footnotetext{
${ }^{16}$ Notice that, for brevity, I use throughout the word 'debt' instead of 'financial liabilities', which is the Economic Outlook terminology.

${ }^{17}$ Briefly, the inflation rate may capture Fisher effects. The size of the debt is predicted to be positively associated to the risk premium by a number of theories, including the one presented in this paper. The primary surplus may be used to gauge the government's resolve towards fiscal consulidation. The real growth rate may provide an indication of future tax income for the government. The contribution of these factors to the interest cost of debt is the focus of the Caselli et al. (1996) paper. Hence, for the sake of brevity I do not discuss, in what follows, the coefficients associated with these controls in Table 1. Here I simply remark that they are generally of the expected sign and magnitude.
} 


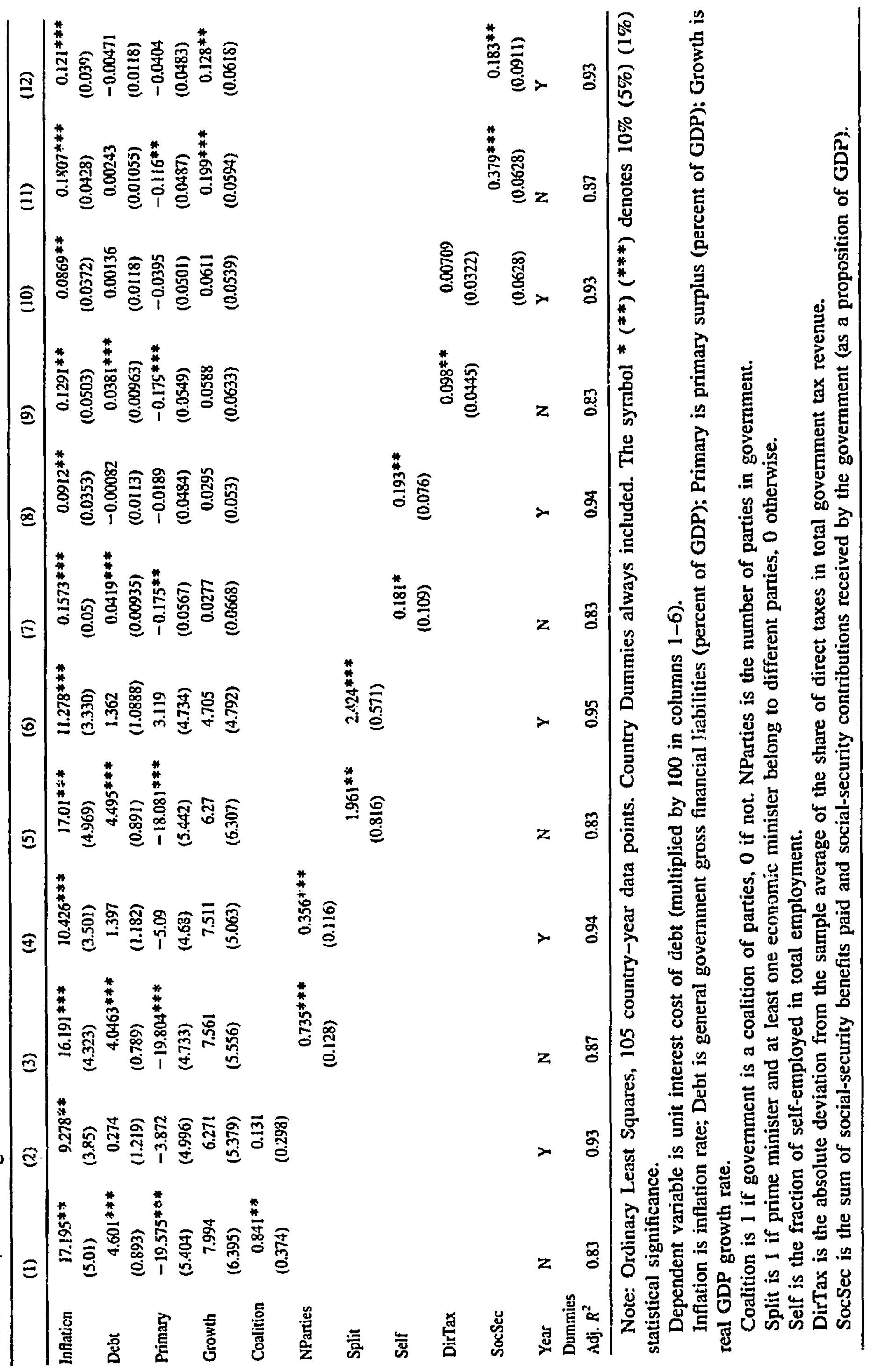


degrees of freedom. In what follows I report results both with and without time effects. Not surprisingly, the diminished degrees of freedom in the regressions with year dummies result in less precise estimates than when only country dummies are included.

I try, one at a time, three indicators of the coalitional nature of the government (as constructed by Kontopoulos and Perotti, 1997) and three proxies for tax imbalances. In the first 2 columns of Table 1 I start with a dummy variable that takes the value of one in a country-year in which the government is a coalition of parties and zero if there is a single-party government (Coalition). The coefficients have the sign predicted hy the theory and, when only country dummies are included, they achieve statistical significance. The statistically significant coefficient is also large in magnitude: it implies that ninoving from a single-party government to a coalition government can increase the weighted average interest cost of debt by more than half of a percentage point. Given the size of the debt, this can translate into an extremely large increase in the interest bill. ${ }^{18}$ I further explore the role of coalition governments by regressing the unit cost of diebt on the number of parties in government (NParties). This is similar to the coalition dummy but allows for the coalition premium to become worse if the number of partners in the coalition increases. The idea is that, as the number of groups yielding a veto power increases, it becomes increasingly difficult to tax any given group in order to service the debt. As seen in Section 3, this can increase the likelihood of confidence crisis. The results in columns 3 and 4 of Table 1 provide strong evidence that the coalition premium increases with the number of parties in the government.

In Columns 5 and 6 I use a dummy variable that takes the value of 1 when the prime minister and one of the main economic ministers (e.g. treasury, finance or economy) belong to different parties (Split). There may be coalitions in which the junior parties do not wield enough clout to exercise a real veto power on the decisions of the senior partner. Such coalitions are not necessarily expected to be associated with a coalition premium. The Split variable singles out those coalitions in which at least two distinct parties exercise considerable power on economic issues. Consistent with the predictions of the model, the coefficients are again positive and large both economically and statistically.

Measuring tax-imbalances is much harder than observing types of governments. However, I now turn to an attempt to capture variables that may proxy for the extent of tax imbalance in an economy. As argued in Section 2, income-tax evasion is likely to be an important source of tax imbalances. Because the self-employed have much better opportunities for tax evasion than wage earners,

\footnotetext{
${ }^{18}$ Roubini and Sachs (1989) find that countries with coalition governments tend to have larger deficits. Hence, the fact that I am controlling for the size of the debt and the primary surplus is important in making sure that my coalition dummy is not just operating as a proxy for the fiscal stance of the government.
} 
the extent of self-employment in an economy may proxy for tax imbalances arising from tax evasion. In columns 7 and 8 of Table 1 I report the coefficients on the proportion of self-employed in total employment (Self) in regressions explaining the unit cost of debt. In both specifications a higher incidence of self-employment is associated with higher unit costs of debt servicing. A taximbalance premium is a potential explanation for this result.

The optimal allocation of tax revenues between direct and indirect taxes depends, of course, on a number of unknown parameters, including the elasticity of labor supply and the elasticity of demand for consumption goods. Suppose that, on average, countries in the sample tend to choose this unknown (to us) optimal mix of direct and indirect taxes. Then, the absolute deviation from the sample mean of one country's share of direct taxes in total taxes can be interpreted as a crude approximation to that country's tendency to deviate from the optimai tax structure. Columns 9-10 of Table 1 show that such a measure (DirTax) is positively related to the unit cost of debt. The analysis in Section 2 suggests that deviations from the optimal tax structure will generate a tax imbalance against some groups of tax payers and in favor of others. Hence, $I$ interpret these positive coefficients as suggestive of a tax-imbalance premium.

A prospective, if not current, further source of tax imbalance is the socialsecurity system. As with any pay-as-you-go program, pension entitlements can be interpreted as a form of unequal taxation of two constituencies: the retired (with a negative tax), and the workers. To obtain a measure of the overall incidence of this tax imbalance I take the sum of social-security benefits paid and social-security contributions received by the government, as a proportion of GDP (Soritec). The coefficients reported in columns 11-12 of Table 1 are supportive of the ; Jea that the tax imbalance associated with the social-security system tends to itc cease the risk premium in high-debt countries.

$I$ have performed extensive checks of the robustness of the results reported above. As a general rule, the evidence presented in Table 1 proved extremely robust. In what follows I list all the checks I have performed, but I discuss the results only if they significantly contradict those in the baseline regression. (1) To probe the robustness of my results to the definition of 'high', I have also experimented with other threshold levels of the debt to GDP ratio, such as 0.5 and 1. (2) As an alternative criterion I have included, for each country, all the years in a given decade if the mean debt to GDP ratio in that decade was above 0.6. (3) I applied the criterion for inclusion in the sample to net, rather than gross, debt. Self took a significantly negative coefficient in the specification with country effects. Notice, however, that using high net debt reduces the sample size to 42 , so that the specification with dummies has few degrees of freediom left. (4) While most of the data come from the 1980s, about one quarter comes from the 1970s. I have repeated the analysis with only post-i979 daia. The coefficient of Self took a negative value when no country dummies were included (but not in the more reliable specifications with country and country-year effects). More seriously, the 
coefficients on DirTax took negative values in both specifications with dummies. I also performed robustness checks with respect to the choice of dependent variable. (5) I used net interest payments as a fraction of net government financial liabilities as a measure of the unit cost of debt. (6) Also, I used interest expenditure divided by the contemporaneous stock of debt (instead of lagged). (7) Finally, the OECD data on Ireland's interest expenditure appears at odds with the corresponding series in the IMF's World Economic Outlook. Hence, I have repeated the empirical analysis omitting Ireland.

In sum, ceteris paribus coalition governments tend to incur higher debt-servicing costs per unit of outstanding debt, and measures that are potential proxies for tax imbalances tend to be associated with higher unit interest payments. In view of the extremely crude nature of the proxies employed, one should be extremely cautious in interpreting these results. However, I regard them as suggestive of the existence of coalition and tax-imbalance premia, and, therefore, as broadly supportive of the theoretical insights developed in this paper.

\section{Conclusions}

In this paper I have shown that the distribution of a given amount of tax revenues across taxpayers and tax bases influences the probability of a selffulfilling debt run on the public debt. The more asymmetric the distribution, the more likely a confidence crisis. I have also shown that a government's distributive preferences influence the likelihood of default as well. Contrary to common wisdom, however, the more the government pursues redistributive policies, the lower this likelihood. The more the government seeks to spread tax distortions across social groups, the higher the likelihood. Finally, the distribution of debt matters, too. If the government puts at least some weight on all social groups, then both the probability and the extent of the repudiation will be influenced (in the intuitive way) by how debt holdings are distributed. However, under a regime in which the government is completely identified with a specific constituency, there will be no default irrespective of the distribution of the debt.

I have also provided some empirical evidence in support of the theoretical results. Regression results show that, ceteris paribus, coalition governments tend to incur higher borrowing costs than single-party governments. These 'coalition premia' are increasing in the number of parties in the coalition, and they are particularly severe if the prime minister and at least one major economic minister belong to different parties. Also, the interest cost of debt is higher in countries with a high incidence of self-employment, in countries with a tax structure that is out of line with the sample average, and in countries with large social-security programs. Since I take these three variables to represent potential proxies for tax imbalances, these results point to the existence of 'tax-imbalance premia'.

Both the theoretical analysis and the informal evidence imply that there are 
additional positive side effects to be expected from reforming the tax system towards greater efficiency and fairness. For example, if Italy and Belgium were to fight tax evasion more effectively, in addition to the obvious direct gains in terms of decreased budget deficits and distortions, they could also indirectly benefit from lower interest expenses-due to a fall in the tax-imbalance premium. Similarly, it appears that institutional design has an indirect bearing on the cost of debt. In particular, a political system that discourages coalitions and favours majority ruling should make debt policy easier, thanks to a fall in the coalition premium.

\section{Acknowledgements}

The author wishes to thank Alberto Alesina, Philip Lane, Timothy Lane, Roberto Perotti, Jordan Rappaport and two anonymous referees for useful suggestions. He is also very grateful to Yianos Kontopoulos and Roberto Perotti for sharing their data set. He alone is responsible for remaining errors.

\section{Appendix A}

Substitute from Eqs. (6)-(9) into Eq. (11) and rearrange, to get

$$
\begin{aligned}
& (1-\beta)\left[z(b, 0)-z\left(\frac{b}{2}, \frac{b}{2}\right)\right]> \\
& z(b(1-\beta), 0)-z\left(\frac{1}{2} b(1-\beta), \frac{1}{2} b(1-\beta)\right)
\end{aligned}
$$

Now define $f(x)$ as $z(x, 0)-z(x / 2, x / 2)$, which can be shown to be a convex function of $x$. Then Eq. (11) is verified, because it is equivalent to $(1-\beta) f(x)>f[(1-\beta) x]$.

\section{Keferences}

Aghion, P., Bolton, P., 1990. Government domestic debt and the risk of default: A political-economic model of the strategic role of debt, in: R. Dornbusch and M. Draghi, eds., Public debt management: Theory and history (Cambridge University Press, Cambridge) pp. 125-143.

Alesina, A., Drazen, A., 1991. Why are stabilizations delayed?. Anierican Economic Review 81, 1170-1188.

Alesina, A., Prati, A., Tabellini, G., 1990. Public confidence and debt management: A model and a case study of Italy, in R. Dombusch and M. Draghi, eds., Public debt management: 'Theory and history (Cambridge University Press, Cambridge) pp. 94-117.

Alesina, A., Rosenthai, H., 1995. Partisan politics, divided govemment and the economy (Cambridge University Press, Cambridge).

Calvo, G., 1988. Servicing the public debt: The role of expectations. American Economic Review 78, 647-661. 
Caselli, F., 1992. Nuove teorie del debt management. Politica Economica 8, 301-323.

Caselli, F., Giovannini, A., Lane, T., 1996. Fiscal discipline and the cost of public debt service: Some estimates for countries (IMF) unpublished.

De Broeck, M., 1991. Essays on the financial structure of government debt and government debt management, Ph.D. Thesis (Harvard University).

Diamond, D.W., Dybvig, P., 1983. Bank runs, deposit insurance and liquidity. Journal of Political Economy 91, 401-419.

Drazen, A., Grilli, V., 1993. Benefits of crises for economic reform. American Economic Review 83, 598-607.

Giavazzi, F., Pagano, M., 1990. Confidence crises and public debt management, in R. Dornbusch and M. Draghi, eds., Public debt management: Theory and history (Cambridge University Press, Cambridge) pp. 125-142.

Kontopoulos, Y., Perotti, R., 1997. Fragmented fiscal policy (Columbia University) unpublished.

Milesi-Ferretti, G.M., 1995. Do good or do well? Public debt management in a two-party economy. Economics and Politics 7, 58-74.

Roubini, N., Sachs, J., 1989. Political and economic determinants of budget deficits in the industrial democracies. European Economic Review 33, 903-933.

Spolaore, E., 1993: Policy making systems and economic efficiency: Coalition governments versus majority governments (Université Libre de Bruxelles) unpublished. 